\title{
Long-term fate of the aortic valve after an arterial switch operation
}

\author{
Mauro Lo Rito, MD, ${ }^{\mathrm{a}}$ Mario Fittipaldi, MD, ${ }^{\mathrm{a}}$ Randula Haththotuwa, MD, ${ }^{\mathrm{b}}$ Timothy J. Jones, MD, \\ Natasha Khan, MD, ${ }^{a}$ Paul Clift, MD, ${ }^{\mathrm{b}}$ William J. Brawn, MD, ${ }^{\mathrm{a}}$ and David J. Barron, MD ${ }^{\mathrm{a}}$
}

\section{ABSTRACT}

Objective: To evaluate long-term performance of the aortic valve after an arterial switch operation (ASO), in terms of regurgitation and reoperation.

Methods: A longitudinal analysis of patients who underwent an ASO between 1988 and 1998 at the Birmingham Children's Hospital. Any type of aortic valve surgery after ASO was censored. To determine progression of aortic valve regurgitation, cardiology follow-up and echocardiograms from the operation until 2012 were reviewed.

Results: A total of 362 patients underwent ASO; median age was 8 days. Ventricular septal defect was present in 151 , aortic coarctation in 39 , and interrupted aortic arch in 6 patients. The trap door technique was used for coronary translocation when possible; $4.1 \%$ had intramural coronaries. There were 331 alive patients; follow-up was complete at $93 \%$; median duration was 16 years (interquartile range, 12-18.2 years). Overall survival at 10 and 20 years was $97.6 \%$ and $95.2 \%$, respectively. Aortic valve reoperation occurred in 5 patients, giving freedom from aortic surgery of $99.3 \%$ and $97.7 \%$ at 10 and 20 years, respectively. Reoperations were aortic valve replacement (3), Bentall operation (1), and aortic valve repair (1). Freedom from $\geq$ moderate regurgitation at 10 with 20 years was $97 \%$ to $80 \%$, respectively. Degree of regurgitation immediately after ASO was strongly predictive of late aortic valve function: patients discharged with mild regurgitation had a significantly increased risk of progression compared with those with no regurgitation (20 years of freedom from $\geq$ moderate regurgitation, $50 \%$ vs $96 \%, P=.0000$ ).

Conclusions: Reoperation on the aortic valve is rarely necessary, even late after an ASO, but a significant number of patients do have late aortic regurgitation and continue to need observation. (J Thorac Cardiovasc Surg 2015;149:1089-94)

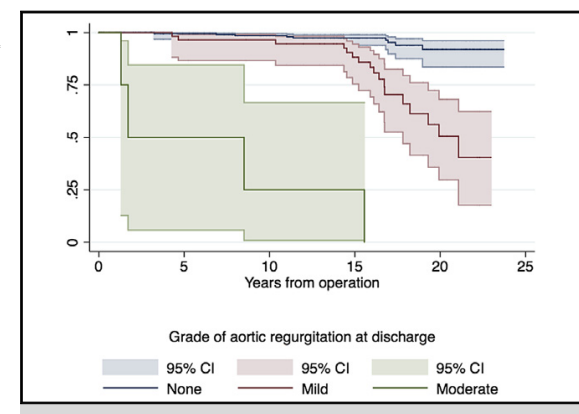

Freedom from aortic regurgitation $\geq$ moderate by the degree of aortic valve regurgitation at discharge.

\section{Central Message}

Aortic valve reoperation is rarely necessary $(1.6 \%)$ but late regurgitation develops in a significant number of patient $(20 \%)$ even late after ASO. It is more common in patients with mild regurgitation immediately after ASO compared with patient's competent valve. Follow-up is essentia because aortic regurgitation can develop 20 years after ASO

\section{Perspective}

Aortic valve competence represents the most impacting complication in the long-term patient's outcome after ASO. In the current era, aortic valve reoperation is a rare event but our data show that a progressive deterioration of aortic regurgitation tends to occur after 15-20 years from the initial repair if patients had only mild regurgitation initially. This finding highlights the importance of a close long-term cardiac follow-up and health care planning because we will face an increased number of patients who will require aortic valve surgery in the next future after ASO.

See Editorial page 968.
The first successful arterial switch operation (ASO) was described by Jatene and colleagues ${ }^{1}$ in 1976 and rapidly replaced the atrial switch operations that had been performed prior to that point for treatment of transposition of the great arteries (TGA). The ASO is considered the standard procedure for correction of TGA, with low mortality and morbidity. ${ }^{2-5}$ Despite the excellent surgical results and the

\footnotetext{
From the Department of Cardiac Surgery, ${ }^{\text {a }}$ Birmingham Children's Hospital, Birmingham; and Grown-Up Congenital Heart Unit, ${ }^{\mathrm{b}}$ Queen Elizabeth Hospital, Birmingham, United Kingdom.

Read at the 94th Annual Meeting of The American Association for Thoracic Surgery, Toronto, Ontario, Canada, April 26-30, 2014.

Received for publication Aug 27, 2014; revisions received Oct 29, 2014; accepted for publication Nov 28, 2014; available ahead of print Dec 26, 2014

Address for reprints: Mauro Lo Rito, MD, Department of Cardiac Surgery, Birmingham Children's Hospital National Health Service Trust, Steelhouse Lane, Birmingham B4 6NH, United Kingdom (E-mail: mauro.lorito@gmail.com). $0022-5223 / \$ 36.00$

Copyright (c) 2015 by The American Association for Thoracic Surgery http://dx.doi.org/10.1016/j.jtcvs.2014.11.075
}

high quality of life ${ }^{6}$ that comes after ASO, a small proportion of patients have required reintervention for right ventricular tract obstruction, ${ }^{7}$ left ventricular outflow tract obstruction, coronary artery problems, aortic root dilatation, and aortic valve regurgitation.

Studies on large cohorts of patients have shown, in a midterm follow-up, a significant dilatation of the aortic root in the majority of patients, but with a low incidence of aortic valve regurgitation. ${ }^{9}$ As we now approach the fourth decade since the first ASO, we have an opportunity to focus on the older patients and examine the longerterm impact of this operation on aortic valve function. This study aimed to concentrate on the cohort of patients who are 15-25 years past their ASO, to define the incidence and progression of aortic valve problems.

\section{MATERIALS AND METHODS}

The aim of the study is to investigate long-term performance of the aortic valve; for this reason, we perform a retrospective longitudinal 


\section{Abbreviations and Acronyms \\ ASO $=$ arterial switch operation \\ $\mathrm{Cx}=$ circumflex coronary branch \\ $\mathrm{IQR}=$ interquartile range \\ $\mathrm{LAD}=$ left anterior descending coronary artery \\ $\mathrm{R} \quad=$ right coronary artery \\ $\mathrm{TGA}=$ transposition of the great arteries}

analysis of all the patients who underwent ASO for TGA between January 1988 and December 1998 at the Birmingham Children's Hospital, Birmingham, United Kingdom. Patients who died in the hospital were excluded from aortic valve performance analysis because long-term valve performance could not be assessed in those cases.

The end points were: (1) the grade of aortic valve regurgitation; (2) aortic valve stenosis; (3) aortic valve reoperation (aortic valve plasty or replacement, aortic root surgery); and (4) long-term survival. Patients' history, demographic data, diagnosis, pre-ASO procedures, hospital course, and discharge echocardiogram results were obtained from hospital records. Follow-up data were obtained by reviewing cardiologic charts and echocardiograms from Birmingham Children's Hospital and from the Grown-Up Congenital Heart Unit of the Department of Cardiology at the Queen Elizabeth Hospital of Birmingham, Birmingham, United Kingdom, where the patients were transitioned for follow-up at age 16 years. If patients were followed outside the Birmingham hospital network, data were retrieved from the other involved hospital cardiology departments.

Review of echocardiograms and reports, covering the period from the time of the operation to the most recent available, was performed for each patient. Degree of aortic valve regurgitation (classified as none, mild, moderate, or severe), aortic stenosis, and the presence of left ventricular outflow tract obstruction were recorded. Progression of aortic valve regurgitation was defined by the first echocardiogram in which worsening of the previous regurgitation class was recorded, and the worsening had to be confirmed in the later echocardiograms. Progression was noted only when confirmed by subsequent reports, to eliminate differences among echocardiogram operators for borderline cases.

The study was approved by the Scientific Committee of the Department of Cardiac Surgery at the Birmingham Children's Hospital. Data were analyzed using Stata, Release 12 (StataCorp, College Station, Tex). Data were expressed as mean $\pm \mathrm{SD}$, and as median and range when appropriate. Tests used were the Student $t$ test, $\chi^{2}$ analysis, and Fisher exact test; Kaplan-Meier method analysis was performed for event-free and survival curves; the log-rank test and Cox regression were used for freedomfrom-event-curve group comparison.

\section{RESULTS}

From 1988 to 2012, at the Birmingham Children's Hospital, 662 patients underwent an ASO for TGA. The population of interest for the study, from January 1988 to December 1998, consisted of 362 patients; 264 (73\%) were male, and $98(27 \%)$ were female. Median weight was $3.45 \mathrm{~kg}$ (range, 1.8-22.4, interquartile range [IQR]: 3$3.8 \mathrm{~kg}$ ), and median age at operation was 8 days (range, 1 day to 10.7 years; IQR: 5-17 days); the older patients underwent ASO later, owing to complex anatomy.

The main diagnoses were TGA with intact ventricular septum in $211(58.3 \%)$ patients, and TGA with ventricular septal defect in $151(41.7 \%)$. Among the last group, 30 patients had Taussig-Bing malformation. Other minor associated cardiac anomalies are listed in Table 1. Coronary pattern was normal (1LAD,Cx;2R) in $79 \%$ of the patients, and among these, $11(3 \%)$ had an early take-off of the $\mathrm{Cx}$ from the LAD. In another 34 patients $(9.3 \%)$, the $\mathrm{Cx}$ originated from the right coronary artery ( $1 \mathrm{LAD} ; 2 \mathrm{R}, \mathrm{Cx})$; the remaining coronary patterns are summarized in Table 1 . Coronary intramural course affected $15(4.1 \%)$ patients in the entire group.

The majority of the patients (302 [83.4\%]) underwent balloon atrial septostomy before ASO; in 21 patients $(5.8 \%)$, pulmonary artery banding was used as palliation before the complete repair that was performed at older ages (median: 240 days; range, 16 days to 10.7 years). All patients underwent an ASO and associated lesion treatment (ie, ventricular septal defect closure and atrial septal defect closure); the trap door technique, as described elsewhere, ${ }^{10}$ was routinely used, except for cases of intramural coronaries in which coronaries were reimplanted using a patch technique. Mean cardiopulmonary bypass time was $112 \pm$ 47 min, and mean aortic cross-clamp time was $77.8 \pm 23$ min.

After the ASO, the chest was left open in 97 (26.8\%) patients, for a median time of 1 day (range, 1-5 days, IQR: 1-2 days). Patients were discharged from the intensive-care unit after a median time of 3 days (range, 1-45 days, IQR: 2-4 days) and from the hospital after a median time of 8 days (range, 4-56 days, IQR: 7-12 days).

A total of $31(8.56 \%)$ in-hospital deaths occurred, and those patients were excluded from further analysis. The majority of the deaths ( 23 of 31 patients) were cases of complex transposition including Taussig-Bing with arch obstruction (10 of 31 patients) and/or were brought to the operating room in emergency condition. Two-thirds of the hospital deaths ( 23 of 31 ) occurred during the first 5 years of the ASO program at the Birmingham Children's Hospital, from 1988 to 1993, giving a hospital mortality of $6.3 \%$. In the subsequent 5 years, the mortality dropped to $2.2 \%$ (8 of 31 patients).

Among the 331 patients discharged at home, $10(3 \%)$ late deaths occurred, so survival after discharge was $98 \%$, $97.6 \%$, and $95.2 \%$, at 5,10 , and 20 years, respectively (Figure 1). Median follow-up duration was 16 years (IQR: 12-18.2 years) and was complete at $93.3 \%$; for 22 patients, retrieving consistent information about clinical and aortic valve status after discharge was not possible.

\section{Aortic Valve Status}

Among the 331 patients discharged from the hospital, the grade of aortic regurgitation was none in $269(81.3 \%)$ patients, mild in $58(17.5 \%)$, and moderate in $4(1.2 \%)$; no patient was discharged with severe aortic valve regurgitation. Status of the aortic valve for the duration of the entire follow-up period was available in 309 patients, and the grade of regurgitation at last follow-up was none in 212 
TABLE 1. Anatomic characteristics of patients before arterial switch operation

\begin{tabular}{lcc}
\hline \multicolumn{1}{c}{ Anatomic characteristics } & $\begin{array}{c}\text { Number of } \\
\text { patients }(\mathbf{n}=\mathbf{3 6 2})\end{array}$ & $\begin{array}{c}\text { Frequency } \\
(\%)\end{array}$ \\
\hline TGA-IVS without associated anomalies & 204 & 56.3 \\
TGA with associated anomalies & 158 & 43.7 \\
Associated anomalies & & \\
VSD & 151 & 41.71 \\
Coarctation & 39 & 10.77 \\
Taussig-Bing & 30 & 8.29 \\
LVOTO & 22 & 6.08 \\
RVOTO & 13 & 3.59 \\
Interrupted aortic arch & 6 & 1.66 \\
Coronary pattern (Leiden Classification) & & \\
Normal anatomy (1LAD,Cx;2R) & 286 & 79 \\
PostCx (1LAD;2R,Cx) & 34 & 9.39 \\
Ant right, post left (1R;2LAD,Cx) & 19 & 5.25 \\
Ant post (1R,LAD;2Cx) & 9 & 2.49 \\
Post left (2R,LAD,Cx) & 5 & 1.38 \\
(1LAD;2R;2Cx) & 5 & 1.38 \\
(2R,2LAD,Cx) & 4 & 1.10 \\
\hline
\end{tabular}

$T G A$, Transposition of the great arteries; $I V S$, intact ventricular septum; $V S D$, ventricular septal defect; $L V O T O$, left ventricular outflow tract obstruction; $R$ VOTO, right ventricular outflow tract obstruction; $L A D$, left anterior descending; $C x$, circumflex coronary branch; $R$, right coronary; ant, anterior; post, posterior.

$(69.6 \%)$ patients, mild in $67(21.7 \%)$, moderate in 24 $(7.8 \%)$, and severe in $3(0.9 \%)$. The overall actuarial freedom from aortic regurgitation that was $\geq$ moderate was $98 \%$ at 5 years, and it decreased to $97 \%, 94 \%$, and $80 \%$ at 10,15, and 20 years, respectively (Figure 2, A). Patients were divided into 3 groups (none, mild, moderate) according to the grade of aortic regurgitation at the time of discharge after their ASO, to evaluate valve performance in the long term.

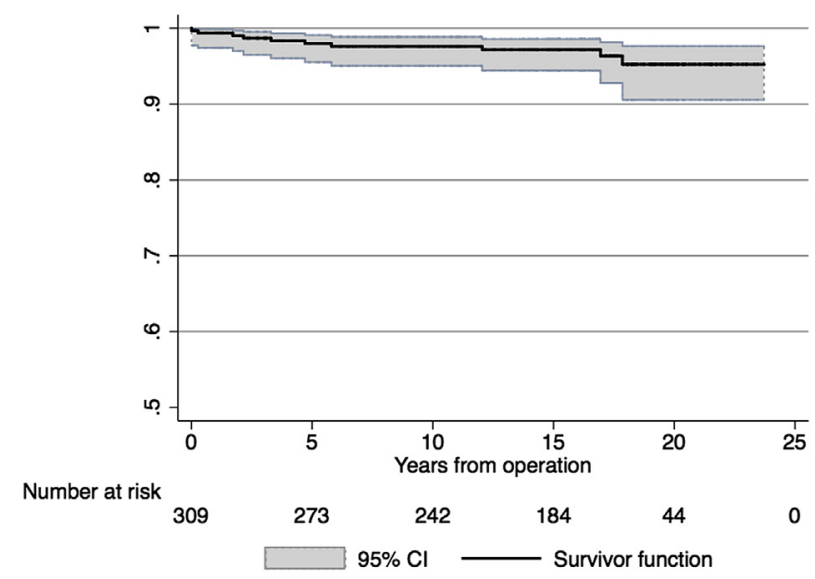

FIGURE 1. Survival curve estimate after discharge for arterial switch operation: Kaplan-Meier survival estimate after discharge is $98 \%$, $97.6 \%$, and $95.2 \%$, at 5,10 , and 20 years, respectively. $C I$, Confidence interval.
Freedom from significant aortic regurgitation (moderate or severe) for patients discharged with no aortic regurgitation was $99.5 \%, 98.5 \%, 97.4 \%$, and $91.9 \%$, at $5,10,15$, and 20 years, respectively (Figure 2, B); for patients discharged with mild aortic valve regurgitation, it was $96.4 \%, 96.4 \%, 88.2 \%$, and $50 \%$, respectively, at the same time points (Figure 2, B). Patients discharged with mild aortic regurgitation have a significantly higher progression to moderate grade compared with patients discharged with no regurgitation (hazard ratio: $3.26, P=.000$ ).

In the group of patients discharged with no aortic regurgitation, only $9(3.4 \%)$ developed moderate or severe aortic valve insufficiency in a median time of $12.3 \pm$ 5.5 years; among them, 2 required aortic valve surgery (Figure 3). For patients discharged with mild aortic regurgitation (58 patients), 17 (29.3\% of the group) progressed to the higher regurgitation class after a median time of $15 \pm 4.7$ years, although none of them has required aortic valve surgery to date (Figure 3 ). Among the 4 patients discharged with moderate aortic regurgitation, 3 of them required aortic valve surgery ( 2 needed replacement, and 1 needed repair).

At follow-up, 3 patients have severe aortic regurgitation but have not yet required aortic surgery, owing to lack of symptoms and a nondilated left ventricle, but they are likely to need it in the future. One of these patients was discharged without any aortic valve regurgitation, and for the remaining 2, the grade of regurgitation at discharge was mild. During the study period, no patient developed significant aortic valve stenosis or left ventricular outflow tract obstruction. The presence or progression of aortic regurgitation was not associated with the presence of a ventricular septal defect, with age at operation, or with use of pulmonary artery banding as palliation before the ASO.

\section{Aortic Valve Reoperation}

Aortic valve operation, with or without aortic root surgery, was required in 5 of $309(1.6 \%)$ of the patients during follow-up. For these 5 patients, 3 had a diagnosis of TGA without associated intracardiac anomalies, and 2 had a diagnosis of TGA with ventricular septal defect. In the 309 patients who were followed, freedom from aortic valve reoperation was $99.6 \%, 99.3 \%$, and $97.7 \%$ at 5,10 , and 20 years, respectively (Figure 4 ).

In the 3 patients with simple TGA, 1 had an anomalous coronary pattern with an intramural left coronary artery and underwent an ASO with unroofing of the intramural left coronary artery. During follow-up, he developed left pulmonary artery stenosis and moderate aortic valve regurgitation that were investigated with a cardiac catheter, revealing a previously undetected stenosis of the left coronary artery. At 18 months after the ASO, he underwent patch enlargement of the left pulmonary artery, and 


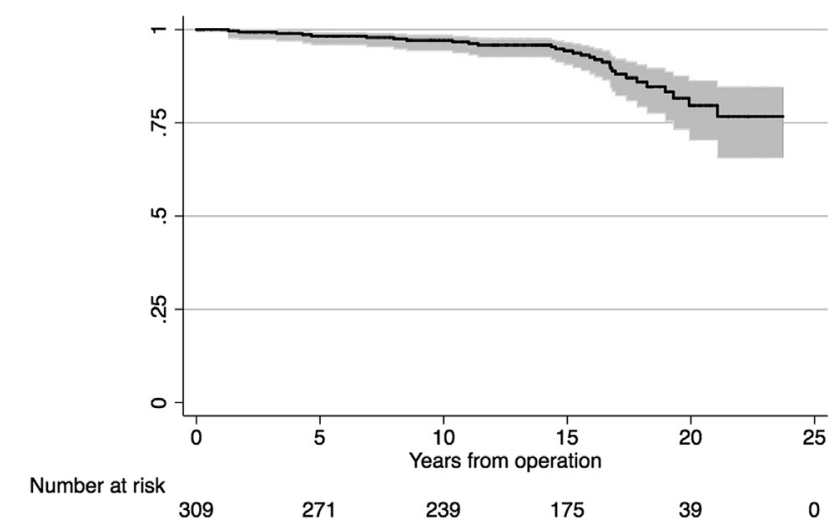

A $\square 95 \% \mathrm{Cl} \longrightarrow$ Freedom from aortic regurgitation>= moderate

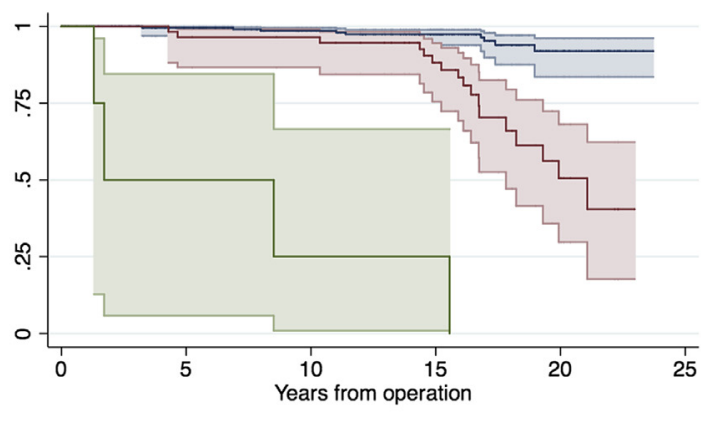

Grade of aortic regurgitation at discharge

$95 \% \mathrm{Cl}-95 \% \mathrm{Cl} \square \mathrm{Cl}$ None Mild Moderate

FIGURE 2. Freedom from aortic regurgitation that is moderate or more than moderate: (A) overall freedom from aortic regurgitation that is $>$ moderate is $98 \%$ (5 years), $97 \%$ (10 years), $94 \%$ ( 15 years), and 80\% (20 years); (B) freedom from aortic regurgitation that is $>$ moderate, by aortic valve regurgitation grade at discharge: no aortic regurgitation (blue line: $99.5 \%$ [ 5 years], $98.5 \%$ [10 years], $97.4 \%$ [15 years], $91.9 \%$ [20 years]); mild aortic regurgitation (red line: $96.4 \%$ [ 5 years], $96.4 \%$ [10 years], $88.2 \%$ [15 years], 50\% [20 years]); moderate aortic valve regurgitation (green line: value not reported because group was formed by only 3 observations). CI, Confidence interval.

coronary bypass with left internal mammary to the LAD. The moderate aortic valve regurgitation was not addressed at the time of the operation, and his postoperative course was characterized by refractory cardiac failure and left ventricle dilatation. An aortic root replacement with an aortic homograft was performed, as a salvage procedure, but the patient did not improve and subsequently died in the hospital from progressive low cardiac output.

The other 2 patients who had simple TGA were discharged after the ASO, with moderate aortic valve regurgitation. One required mechanical aortic valve replacement after 11.5 years; the other required aortic valve plasty after 8.5 years. Both reoperations were uneventful, and both patients were in good clinical condition at last follow-up.

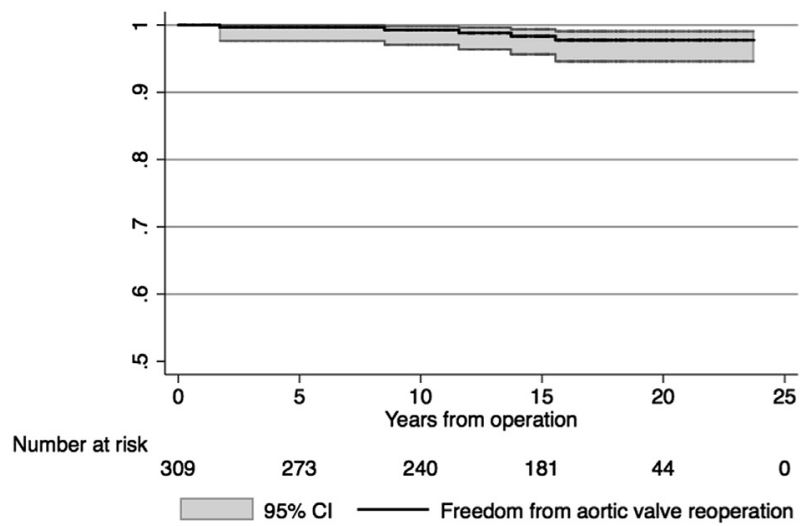

FIGURE 3. Freedom from aortic valve reoperation after arterial switch operation: Freedom from aortic valve reoperation was $99.6 \%, 99.3 \%$, and $97.7 \%$ at 5,10 , and 20 years, respectively. $C I$, Confidence interval.
The 2 patients with TGA and ventricular septal defect required pulmonary artery banding as a staged approach, and complete repair, which was achieved when they were aged 3 and 8 months, respectively. Aortic valve regurgitation at discharge after the ASO was mild and moderate, respectively, and progressed to the point of necessitating valve replacement. The type of reoperations performed were, respectively, mechanical aortic valve replacement and a Bentall operation, after 13.7 and 15.5 years after the ASO. The postoperative course after the reoperation was uneventful, and patients did not require further surgery. Other surgical procedures after the ASO were pulmonary artery stenosis relief (24 of 331 [7.2\%] patients), repair of recurrent aortic arch obstruction (3 of 331 [0.9\%]), mitral valve surgery (3 of 331 $[0.9 \%]$ patients), and permanent pacemaker implantation in 2 patients.

\section{DISCUSSION}

The arterial switch operation is the gold-standard procedure for correction of TGA. Early and midterm results have been proven to be excellent in terms of survival, ${ }^{4,5}$ incidence of reoperation, ${ }^{4,11,12}$ and comorbidities related to coronary translocation. ${ }^{7,13,14}$ The hospital mortality of $8.56 \%$ in this series is almost entirely related to complex transposition (ie, Taussig-Bing anomalies), with associated severe anomalies (ie, aortic arch hypoplasia), similar to what has been reported by other large series describing the results of ASOs for the same time period. ${ }^{11,15}$ Longterm mortality after an ASO was low, accounting for 3\% of the patients with an excellent estimated survival after discharge of $98 \%, 97.6 \%$, and $95.2 \%$, at 5,10 , and 20 years, respectively (Figure 1). 


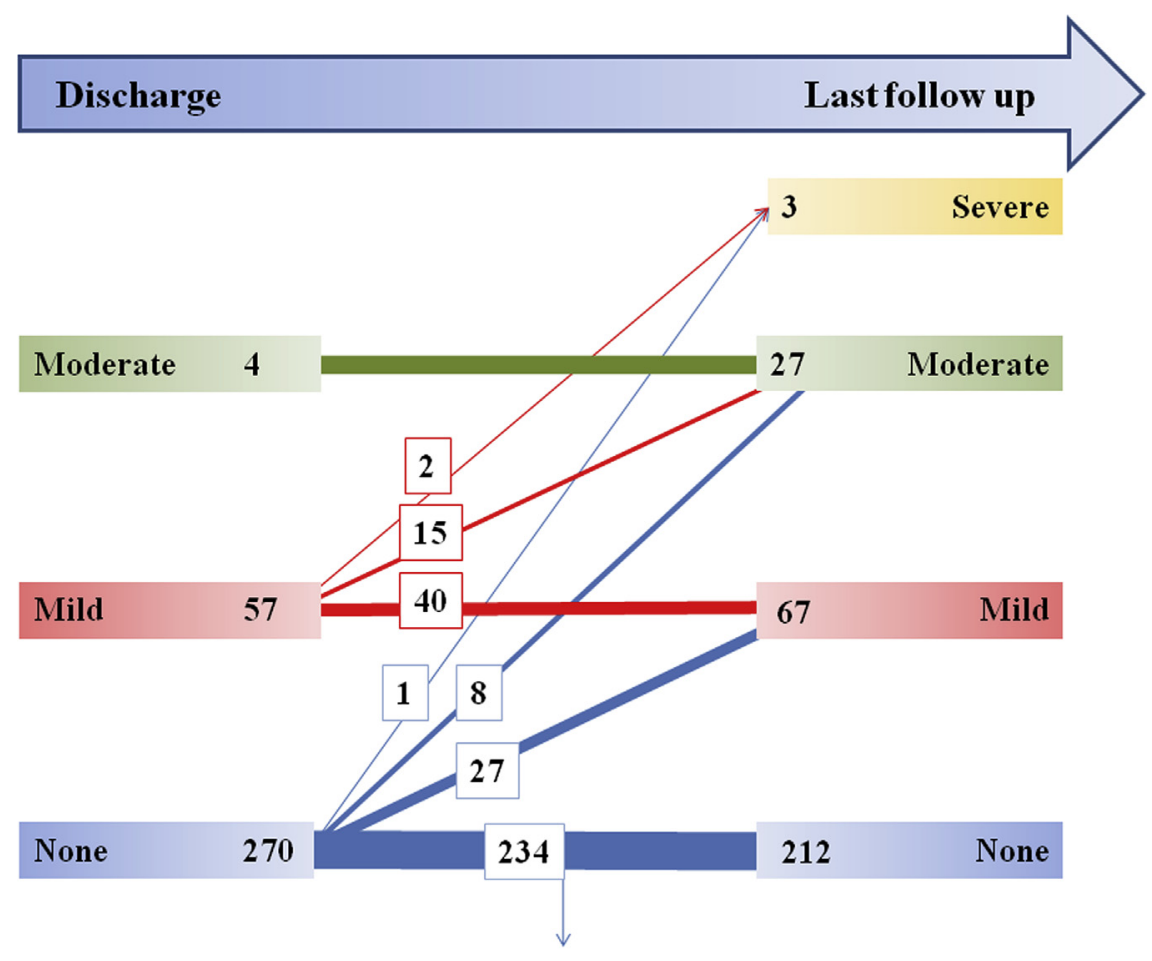

Lost at follow up : 22

FIGURE 4. Progression of aortic valve regurgitation from discharge to follow-up: patient plotted by grade of aortic regurgitation at discharge (blue $=$ none; red $=$ mild; green $=$ moderate). The arrows indicate the changes in aortic regurgitation class from discharge to the last follow-up for each individual group, with the absolute number of patients reported in the corresponding boxes.

Aortic valve regurgitation after an ASO seems to be a multifactorial process that results in progressive aortic root dilatation and subsequent progressive aortic valve regurgitation. Aortic root dilatation and aortic valve regurgitation have been found to be associated with the presence of ventricular septal defect, pulmonary artery banding, aortic/pulmonary artery mismatch, ${ }^{8,16,17}$ and postoperative geometry of aortic root, ${ }^{18}$ as reported in several studies. ${ }^{8,16,17}$ These findings had not been confirmed in larger series, ${ }^{9,14}$ and in our study, we did not detect those as risk factors for aortic valve reoperation or progression of aortic valve regurgitation.

Coronary reimplantation technique can have a great impact on aortic root geometry and can deform the aortic sinus geometry, predisposing it to later dilatation. The trap door technique has been reported to be associated with an increased rate of aortic valve regurgitation. ${ }^{19}$ We routinely use trap door coronary translocation, but we aim to implant coronary arteries above the sinotubular area when possible, avoiding potential alteration of the aortic sinus geometry and at the same time preventing coronary artery kinking.

The results showed very good aortic valve competence after an ASO, and only $1.2 \%$ of the patients had postoperative moderate aortic valve regurgitation. Most of the patients $(81 \%)$, when discharged after the operation, did not have any valve regurgitation, and only $17 \%$ showed mild regurgitation. Progression of aortic valve regurgitation to a clinically significant grade (moderate or severe) occurs rarely in the first 10 to 15 years after an ASO, giving a freedom from significant aortic regurgitation (> moderate) of $97 \%$ and $94 \%$, respectively, for these time points. Although aortic functional status seems to be relatively stable in the first 15 years, a greater deterioration of valve competence occurs between 15 and 20 years of follow-up (Figure 2), and freedom from regurgitation that is more than moderate decreases from $94 \%$ to $80 \%$ at 20 years.

An important finding of this study is the association between aortic regurgitation immediately after the ASO and its late functional outcome. Progression to more-thanmoderate aortic valve regurgitation occurred in only $3.4 \%$ of the patients discharged with no aortic regurgitation. Conversely, patients discharged with mild aortic regurgitation have an incidence of progression to moderate regurgitation of $29 \%$, which is significantly higher compared with the previous group $(P=.000)$. These patients, who were discharged from the hospital after an ASO with even mild aortic regurgitation, have a significantly increased risk of developing moderate regurgitation, with a hazard ratio of 3.26 at 20 years.

The need for aortic valve surgery after an ASO is extremely low up to 15 years, but it tends to increase slightly in the years after that, in accordance with the progression of 
aortic valve regurgitation. Reoperation can be very challenging from a surgical point of view (difficult access to the aortic root in view of the Lecompte maneuver, difficult coronary patterns, previous surgery on the right ventricular outflow tract or pulmonary arteries), but patient survival and outcome are good if the operation has been carefully planned. ${ }^{8}$

\section{CONCLUSIONS}

The overall performance of the aortic valve after the ASO is very good for a long time, and the need for late reoperation on the aortic valve is very low $(1.6 \%)$. However, progression of aortic valve regurgitation to a moderate degree after an ASO can occur in $20 \%$ of patients after 20 years and is more common in patients who had at least mild regurgitation immediately after the ASO. Patients who have a competent valve immediately after the ASO are very unlikely $(3.4 \%)$ to develop any late regurgitation. Continued follow-up is essential, as the current actuarial curves suggest that progressive aortic regurgitation is still developing at 20 years post-ASO.

\section{Conflict of Interest Statement}

Dr Clift reports lecture fees from Actelion Pharmaceuticals. All other authors have nothing to disclose with regard to commercial support.

\section{References}

1. Jatene AD, Fontes VF, Paulista PP, Souza LC, Neger F, Galantier M, et al. Anatomic correction of transposition of the great vessels. J Thorac Cardiovasc Surg. 1976;72:364-70.

2. Trusler GA, Castaneda AR, Rosenthal A, Blackstone EH, Kirklin JW. Current results of management in transposition of the great arteries, with special emphasis on patients with associated ventricular septal defect. JAm Coll Cardiol. 1987;10:1061-71.

3. Castaneda AR, Trusler GA, Paul MH, Blackstone EH, Kirklin JW. The early results of treatment of simple transposition in the current era. J Thorac Cardiovasc Surg. 1988;95:14-28.

4. Williams WG, McCrindle BW, Ashburn DA, Jonas RA, Mavroudis C, Blackstone EH. Outcomes of 829 neonates with complete transposition of the great arteries 12-17 years after repair. Eur J Cardiothorac Surg. 2003; 24:1-9.

5. Fricke TA, d'Udekem Y, Richardson M, Thuys C, Dronavalli M, Ramsay JM, et al. Outcomes of the arterial switch operation for transposition of the great arteries: 25 years of experience. Ann Thorac Surg. 2012;94:139-45.

6. Culbert EL, Ashburn DA, Cullen-Dean G, Joseph JA, Williams WG, Blackstone EH, et al. Quality of life of children after repair of transposition of the great arteries. Circulation. 2003;108:857-62.

7. Kempny A, Wustmann K, Borgia F, Dimopoulos K, Uebing A, Li W, et al. Outcome in adult patients after arterial switch operation for transposition of the great arteries. Int J Cardiol. 2013;167:2588-93.

8. Mavroudis C, Stewart RD, Backer CL, Rudra H, Vargo P, Jacobs ML. Reoperative techniques for complications after arterial switch. Ann Thorac Surg. 2011; 92:1747-54.

9. Marino BS, Wernovsky G, McElhinney DB, Jawad A, Kreb DL, Mantel SF, et al. Neo-aortic valvar function after the arterial switch. Cardiol Young. 2006;16:481-9.

10. Brawn WJ, Mee RB. Early results for anatomic correction of transposition of the great arteries and for double-outlet right ventricle with subpulmonary ventricular septal defect. J Thorac Cardiovasc Surg. 1988;95:230-8.

11. Losay J, Touchot A, Serraf A, Litvinova A, Lambert V, Piot JD, et al. Late outcome after arterial switch operation for transposition of the great arteries. Circulation. 2001;104(12 Suppl 1):I121-6.

12. Angeli E, Raisky O, Bonnet D, Sidi D, Vouhé PR. Late reoperations after neonatal arterial switch operation for transposition of the great arteries. Eur $J$ Cardiothorac Surg. 2008;34:32-6.

13. Legendre A, Losay J, Touchot-Koné A, Serraf A, Belli E, Piot JD, et al. Coronary events after arterial switch operation for transposition of the great arteries. Circulation. 2003;108(Suppl):II186-90.

14. Raju V, Burkhart HM, Durham LA III, Eidem BW, Phillips SD, Li Z, et al. Reoperation after arterial switch: a 27-year experience. Ann Thorac Surg. 2013;95: 2105-12.

15. Wernovsky G, Mayer JE Jr, Jonas RA, Hanley FL, Blackstone EH, Kirklin JW, et al. Factors influencing early and late outcome of the arterial switch operation for transposition of the great arteries. J Thorac Cardiovasc Surg. 1995;109: 289-301.

16. Lange R, Cleuziou J, Hörer J, Holper K, Vogt M, Tassani-Prell P, et al. Risk factors for aortic insufficiency and aortic valve replacement after the arterial switch operation. Eur J Cardiothorac Surg. 2008;34:711-7.

17. Losay J, Touchot A, Capderou A, Piot JD, Belli E, Planché C, et al. Aortic valve regurgitation after arterial switch operation for transposition of the great arteries: incidence, risk factors, and outcome. J Am Coll Cardiol. 2006;47: 2057-62.

18. Jhang WK, Shin HJ, Park J-J, Yun TJ, Kim YH, Ko JK, et al. The importance of neo-aortic root geometry in the arterial switch operation with the trap-door technique in the subsequent development of aortic valve regurgitation. Eur J Cardiothorac Surg. 2012;42:794-9.

19. Formigari R, Toscano A, Giardini A, Gargiulo G, Di Donato R, Picchio FM, et al. Prevalence and predictors of neoaortic regurgitation after arterial switch operation for transposition of the great arteries. J Thorac Cardiovasc Surg. 2003; 126:1753-9. 